\title{
Species-specific chemosensory gene expression in the olfactory organs of the malaria vector Anopheles gambiae
}

Theresa K Hodges ${ }^{1}$, Luciano V Cosme' ${ }^{1}$ Giridhar Athrey ${ }^{1}$, Sharmila Pathikonda', Willem Takken²) and Michel A Slotman ${ }^{1 *}$

\section{Abstract}

Background: The malaria mosquito Anopheles gambiae has a high preference for hum hosts, a characteristic that contributes greatly to its capacity for transmitting human malaria. A sibling spe s, An. quadriannulatus, has a quite different host preference and feeds mostly on bovids. For this reason it do no re ribute to human malaria transmission. Host seeking in mosquitoes is modulated by the olfactory syster, which is primarily housed in the antennae and maxillary palps. Therefore, the detection of differing ho dors by sibling species may be reflected in the expression level of the olfactory genes involved. Accordingly, we conapa, $\mathrm{d}$ d the transcriptomes of the antennae and maxillary palps of An. gambiae and An. quadriannulatus.

Results: We identified seven relatively abundant olfactory rece $r$, nine ionotropic receptors and three odorant binding proteins that are substantially up-regulated in An. g biae ntennae. Interestingly, we find that the maxillary palps of An. gambiae contain a species-specific olfactory rect, $r$, Or52, and five An. gambiae-specific gustatory receptors (AgGr48-52) that are relatively abundant. five gustatory receptors are also expressed in An. gambiae antennae, although at lower level, indicating s/likely 2 in olfaction, rather than gustation. We also document an approximately three-fold higher overall expro on of ol action genes in the maxillary palps of An. quadriannulatus, indicating an important role of this organ the faction system of this species. Finally, the expression of the $\mathrm{CO}_{2}$ receptor genes is five to six-fold high er in the zoophilic An. quadriannulatus, implying a much higher sensitivity for detecting $\mathrm{CO}_{2}$.

Conclusions: These results identify pu ti- human host preference genes in the malaria vector An. gambiae. Interestingly, species-specific e of several gustatory receptors in the olfactory organs indicate a role in olfaction rather than gustation. Adádo, nally, a more expansive role for maxillary palps in olfaction is implicated than previously thous, nt,

\section{Background}

The malaria nosq toes within the Anopheles gambiae complex ary conside, bly in their host preference. Africa's main nth ra ect ro An. gambiae s.s. is highly anthropophilic, whmas L. zoophilic An. quadriannulatus rarely if rer c tacks ymans [1]. This preference of An. gambiae to unn.. hosts is a major factor in its high vectorial capa for human malaria parasites. Conversely, although the zoophilic An. quadriannulatus is a competent malaria

\footnotetext{
* Correspondence: maslotman@tamu.edu

'Department of Entomology, Texas A\&M University, College Station,

TX 77843, USA

Full list of author information is available at the end of the article
}

vector [2], this species does not contribute to malaria transmission because it rarely feeds on human hosts in the field, although it does so readily in the lab $[3,4]$.

Mosquitoes' host attraction is primarily modulated by the olfaction system and An. gambiae females are strongly attracted to emanations from human sweat. Volatiles produced by microflora on the surface of human skin are believed to be responsible for the uniqueness of human odor [5,6]. Over 350 volatiles are found in human sweat [7], and while not all of these play a role in allowing An. gambiae to differentiate human hosts from others, it is likely that a blend of human volatiles is involved. For example, An. gambiae females are attracted to a mixture 
of ammonia, lactic acid, as well as a synergistic blend of ammonia, lactic acid and carboxylic acids [8-10]. Anopheles gambiae and An. quadriannulatus also show different sensitivities to various compounds found in human and animal sweat and/or breath. Therefore, the relative quantities of the constituents of host odor blends, rather than the presence or absence of specific volatiles, could be important in determining attractiveness to various species $[11,12]$.

The antennae and the maxillary palps, the two main olfactory appendages of An. gambiae [13,14], are lined with sensilla that house the olfactory sensory neurons that express olfactory receptors (ORs) [15] or ionotropic receptors (IRs) [16,17]. The binding of odorants to the ORs and IRs triggers the transduction cascade that sends a signal to the olfactory lobes in the cerebral ganglion of the insects [18]. Because of this direct interaction between the receptors and the odorants, differences in host preference between species may be reflected in differences in the expression or molecular structure of the receptors.

Currently, 76 Ors $([19,20]$ and 44 Irs have been identified [21]). ORs are heteromeric ligand-gated ion channels encoded by the highly conserved co-receptor Orco and a specific Or. ORs differ in their tuning breadth and some ORs respond to either a single or small number of odorants, while others respond to a variety of volatiles $[22 / \mathrm{LO}]$. IRs are also heteromeric ligand-gated ion cb. e) but these can contain up to three different sub units $t$ include one or two of the broadly expressed receptor $\operatorname{Ir} 25 a$ and $\operatorname{Ir} 8 a[16,26]$.

In addition to the ORs and IRs, odor nt binding $\mathrm{p}$, oteins (OBPs) play a role in odorant reco nition and interact directly with odorants. OBPs are small, ter-s port molecules abundant in the $n$ nh of tne sensilla. They transport hydrophobic odorants hry. the haemolymph to the receptors (review [27]. Currently, 57 putative Obps have been iden "ed ${ }^{2}-30$, but only 34 Obps are expressed in femare an nae [31]. Some OBPs almost certainly play role in the transport of molecules outside the olfacu system, as two Obps are known to be expressed only in female heads [17].

Differ in the expression level of olfaction genes hav been bscrved between closely related species sedi1 on different hosts. Expression levels of as $\mathrm{n}$ as $3 \%$ of the ORs and $55 \%$ of the OBPs in the ante. differed between the generalists D. melanogaster, $D$. simulans, and their specialist sister-species $D$. sechellia which feeds on the toxic Morinda citrifolia pairs. This is a significantly higher number than observed in other genes [32]. Although some of these changes may be due to neutral evolution, several genes have undergone a major change in expression level along the $D$. sechellia branch, and are thought to be associated with host shifts [32]. For example, Or22a is strongly up-regulated in $D$. sechellia. This receptor is sensitive to a compound emitted by the fruit of $D$. sechellia's host plant Morinda citrifolia [33]. Additionally, D. sechellia lost six Or genes since its split from its generalist sister-species $D$. simulans, which lost none [34]. Furthermore, an increase in olfactory receptor loss was also associated with host specialization in D. erecta [35]. Recently, a comparison between the day-time transcriptome of An. gambiae and An. quadric uatus antennae identified differences in olfaction gene exp that may be related to the difference in ast preference between these sibling species [36] A has en/shown however that olfactory gene expression/fluctuates across the circadian cycle [37]. re, we compare the transcriptome of both the ale nnae and palps of the anthropophilic $n$. gar $x e$ and the zoophilic An. quadriannulatus a ng the arly dark cycle, when both species are actively lking hosts [38,39]. These comparisons fur the $\mathrm{e}_{\mathrm{i}}$ how the divergence of the olfactory organs of thes ies, and allows us to identify species-specific ch osensory genes in An. gambiae that may be re cible tor human host preference.

\section{Results}

\section{Hu hoice assay}

The traction of An. gambiae and An. quadriannulatus or tory strains to human odor vs cow odor was exam-

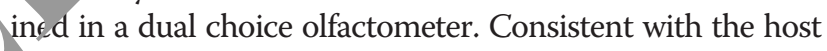
preference of these species in the field and with recent work on laboratory colonies [40], An. gambiae was significantly attracted to human odor $(77 \%, \mathrm{~N}=770, \mathrm{p}<0.0001)$, whereas An. quadriannulatus significantly prefers cow odor $(67 \%, N=330, p=0.0029)$. Therefore, the natural host preference of these species is largely preserved in strains kept in laboratory conditions for many generations.

\section{Gene expression analyses}

Three replicate female antennae RNAseq data sets and two replicate maxillary palps RNAseq data sets were obtained for both An. gambiae and An. quadriannulatus. After quality control screening, $91.0 \%$ of antennal reads from An. gambiae and 87.0\% of antennal reads from $A n$. quadriannulatus mapped to the An. gambiae reference genome. For palps, $86.8 \%$ of the An. gambiae reads and 84.3\% of the An. quadriannulatus reads mapped back to the genome. A higher percentage of total reads obtained for the antennae mapped to a single location in $A n$. gambiae vs An. quadriannulatus ( $83.7 \%$ vs $78.7 \%$ ), whereas fewer reads from the palps mapped to only one location for this species (65.6\% vs $76.4 \%)$. Additionally, the mapping software reported that no An. quadriannulatus reads remained unmapped due to mismatches with the reference genome, hence the difference in read mapping is not due to a divergence between the genomes of the two species. 
We obtained 58.7 to 79.8 million mapped reads for each of the six antennal samples, for a total of 429.5 million mapped reads. Between 52.3 and 75.0 million mapped reads were obtained for each of the four maxillary palp samples, for a total of 261.9 million. Clustering of the variancestabilized transformed counts shows that for both antennae and maxillary palp samples there was relatively little variation among biological replicates relative to differences among tissues and species (Additional file 1: Figure S1).

A total of 9,258 and 9,385 annotated genes were detected in the antennae of An. gambiae and An. quadriannulatus respectively. Of these, 2,593 (28.0\%) are significantly higher expressed (q value of $<0.05$ ) in antennae of An. gambiae and 2,778 (29.6\%) in the antennae of An. quadriannulatus (Figure 1A). In the maxillary palps, 9,824 and 9,994 genes are expressed in An. gambiae and An. quadriannulatus, respectively. Of these, $1,243(12.6 \%)$ genes are significantly up-regulated in An. gambiae and 1,517 (15.2\%) in An. quadriannulatus respectively (Figure $1 \mathrm{~B}$ ).

A gene ontology analysis (GO) was conducted to recover descriptions of molecular and biological function. For this analysis only significantly enhanced genes that were more than 2-fold expressed were considered. This resulted in 564 antennal genes in An. gambiae and 608 antennal genes in An. quadriannulatus (Figure 2, Additional file 2: Figure S2). For the maxillary palps, 870 and 787 genes met t/uese criteria in the two respective species (Additional Figure S3). Of these, 217 genes are shared betw $\eta$ the antenna and palps of An. gambiae, and of thes genes are shared between tissues in An. audrio ulatus (Additional file 4: Figure S4). Not urprisingly, some of the gene ontology (GO) terms $r$ covered in the significantly enhanced genes are con ted to olfaction (e.g., "odorant binding") and rnal transduction (e.g., "response to stimulus", "sign $I$. ducer activity"). Additionally, we found ong representation of terms connected to enzym? act rito For example, "transferase activity" represent. 7\% the up-regulated genes in the antennae of $A r$. mbiae a $4 \%$ of those in the maxillary palps of this species igure 2, Additional file 3: Figure S3).

\section{Olfactory receptors}

Out of the 76 annotated olfactory receptors (Ors), 65 were detected above the threshold in the antennae of at least one species (Additional file 5: Table S1). As expected, the co-receptor Orco is highly expressed in both An. gambiae and $A n$. quadriannulatus female antennae $(1,420$ and 1,756 RPKM, respectively), but is significantly igher in An. quadriannulatus $(\mathrm{q}=0.025)$ (Additiona 5 ) Table S1). Consistent with this observation, the al expression of the specific Ors is highen this species as well (1,738 vs 2,183 RPKM), which is aiso i cte $\mathrm{a}$ in the regression slope (1.20) for Or expr ssion betwe, $n$ species.

A total of 17 Ors are expressed a signi icantly higher level in An. gambiae female a nna able 1, Figure 3]. The expression level of Ors wi cignificantly enhanced expression in $A n$. gamou anged t/ om 2.5 to 42.8 RPKM, but $0 r 36,45,66,69,70,3$ and 75 are noteworthy for being both relc vely abundant (>12.3 RPKM) and substantially $u_{1}$ ( $>1.9$-fold) in An. gambiae. Two expressed 0 (Or8 and 51) were not expressed in the an of $A n$. quadriannulatus, but these were among the las abundant Ors in An. gambiae as well (2.5 and 2.) RPKM, respectively).

1. ontrast to $A n$. gambiae, twenty-eight specific Ors are e ressed at a significantly higher level in the female en hae of $A n$. quadriannulatus. In this species Or1, 9, 23, 33, 46, 61, and 63 stand out by being both highly expressed (RPKM >17.3) and substantially enhanced (>2.0-fold). Four Ors (Or18, 20, 30 and 74) are expressed only in the antennae of An. quadriannulatus, although at low levels $(1.1<\mathrm{RPKM}<6.42)$.

Although no abundant Ors are uniquely expressed in the antennae of either species, our analysis identifies a set of Ors that show clear species-specific enhancement of their antennal expression. Despite these specific differences, a linear regression analysis shows that overall antennal $\mathrm{Or}$ expression is highly correlated between the two species with $\left(R^{2}=0.937\right.$, slope $=1.20$, Figure $\left.3 \mathrm{~A}\right)$.

Strikingly, the overall expression of Ors is much higher in the palps of An. quadriannulatus compared to An.
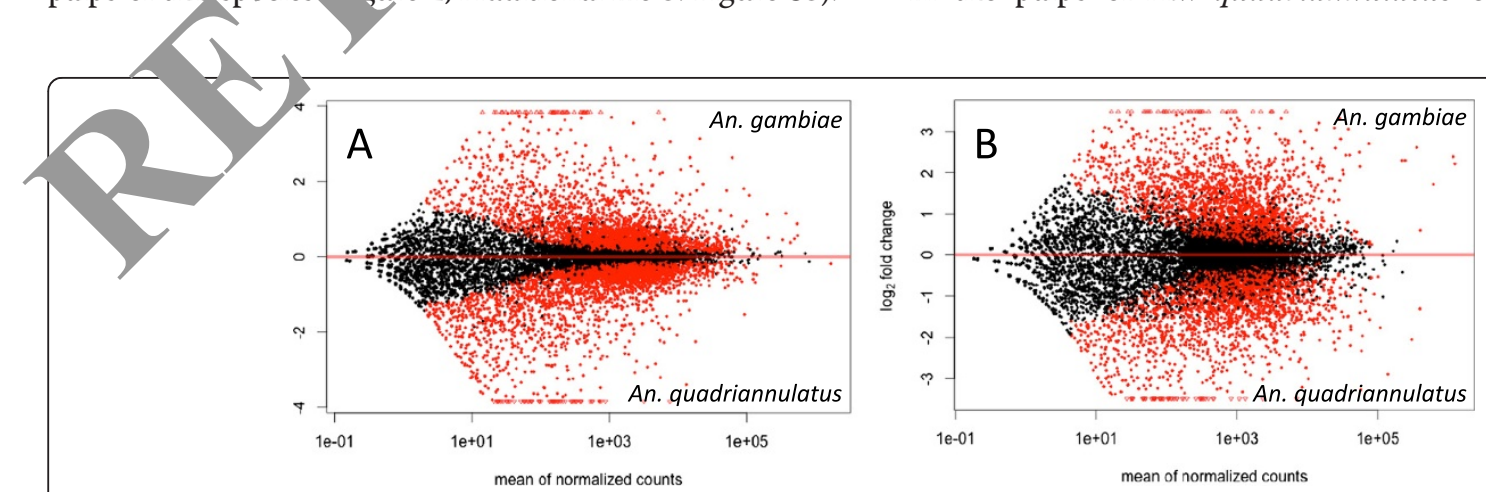

Figure 1 Differential gene expression between An. gambiae and An. quadriannulatus in antennae (A) and maxillary palps (B). The expression of genes indicated in red is statistically significant $(q<0.05)$. 


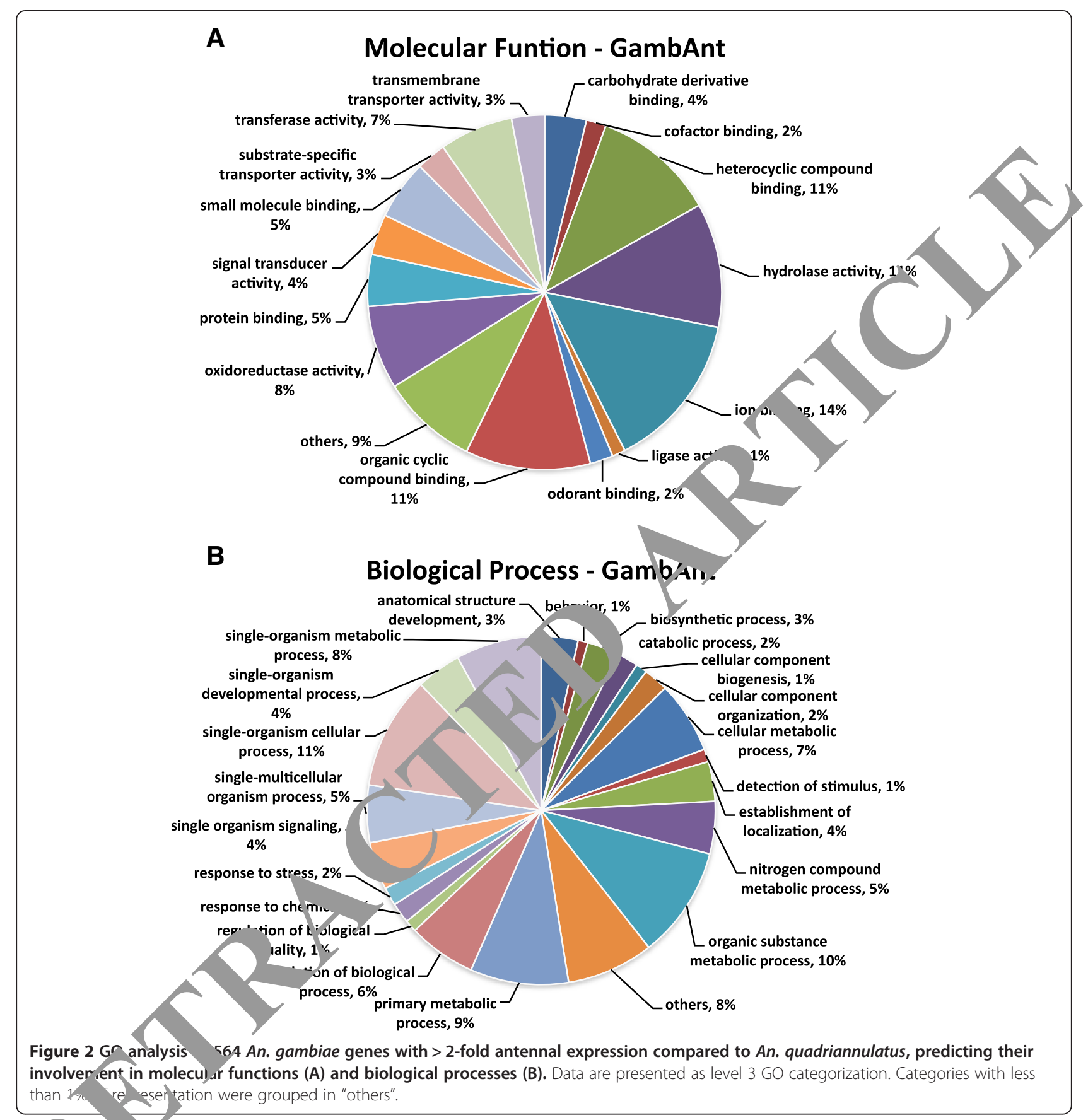

gc. vat. or example, Orco is expressed at 187.3 and 700. PKM in An. gambiae and An. quadriannulatus respectively, and the regression slope for $\mathrm{Or}$ expression between the two species is 2.84 (Figure 4A). This 2.8 to 3.7-fold enhancement of olfactory receptors expression implies a relatively larger importance of the maxillary palps in the olfaction system of An. quadriannulatus.

That being said, Ors are expressed at much lower level in the palps than in the antennae for both An. gambiae (slope $=0.105$, Figure 5A) and An. quadriannulatus (slope $=0.236$, Figure 6A). The number of detected Ors is also substantially less in the maxillary palps. Only 45 specific Ors were detected in the palps of $A n$. gambiae, whereas 53 are present in the An. quadriannulatus female palps (Additional file 6: Table S2). Interestingly, one olfactory receptor, Or52, is unique to the maxillary palps of An. gambiae. This gene is among the seven most abundant Ors in this species (9.55 RPKM), but did not reach our detection threshold in An. quadriannulatus (0.83 RPKM). Furthermore, this gene is all but undetectable in 
Table 1 Olfactory and gustatory genes that are significantly enhanced in the female antennae of An. gambiae vs An. quadriannulatus

\begin{tabular}{|c|c|c|c|c|c|}
\hline Gene & An. gambiae rpkm & An. quadriannulatus rpkm & Fold change & Log2 change & q \\
\hline Or8 & 2.49 & 0.65 & 4.10 & 1.891 & 0.000 \\
\hline Or51 & 2.72 & 0.82 & 3.54 & 1.735 & 0.000 \\
\hline Or66 & 14.09 & 4.66 & 3.19 & 1.640 & 0.000 \\
\hline Or69 & 29.29 & 10.54 & 2.93 & 1.546 & 2.000 \\
\hline Or70 & 18.65 & 6.85 & 2.87 & 1.509 & \\
\hline Or73 & 29.01 & 14.51 & 2.11 & 1.065 & 0.000 \\
\hline Or65 & 2.87 & 1.43 & 2.12 & & 0.000 \\
\hline Or45 & 12.23 & 6.23 & 2.05 & 1.022 & 0.000 \\
\hline Or43 & 5.52 & 2.79 & 2.07 & & 0.000 \\
\hline Or28 & 2.71 & 1.39 & 2.09 & 1.010 & 0.000 \\
\hline Or71 & 8.45 & 4.39 & 2.04 & 1.007 & 0.000 \\
\hline Or75 & 41.79 & 22.98 & 1.92 & 0.934 & 0.000 \\
\hline Or36 & 21.83 & 12.10 & & 0.906 & 0.000 \\
\hline Or54 & 2.81 & 1.71 & & 0.763 & 0.000 \\
\hline Or76 & 10.02 & 6.61 & & 0.675 & 0.000 \\
\hline Or22 & 15.59 & 10.33 & & 0.665 & 0.000 \\
\hline Or81 & 71.66 & 61.77 & 1.22 & 0.282 & 0.013 \\
\hline $1 r 7 s$ & 2.31 & 0.04 & 53.50 & 4.696 & 0.000 \\
\hline Ir75k & 24.50 & 4.66 & 5.49 & 2.433 & 0.000 \\
\hline Ir75h.2 & 84.23 & & 4.94 & 2.283 & 0.000 \\
\hline Ir7w & 58.56 & & 3.81 & 1.922 & 0.000 \\
\hline Ir41n & 56.57 & & 3.40 & 1.743 & 0.000 \\
\hline $\operatorname{lr} 93 a$ & 52.93 & 7.31 & 3.24 & 1.687 & 0.000 \\
\hline Ir100a & 56.35 & & 3.24 & 1.684 & 0.000 \\
\hline $1 r 7 u$ & 7.06 & 2.29 & 3.26 & 1.680 & 0.000 \\
\hline $1 r 7 t$ & 18.64 & 6.99 & 2.82 & 1.482 & 0.000 \\
\hline Ir41C & 18.82 & 7.20 & 2.77 & 1.460 & 0.000 \\
\hline Irrooi & & 2.13 & 2.39 & 1.211 & 0.000 \\
\hline Ir7i & & 1.88 & 1.88 & 0.901 & 0.000 \\
\hline $1 r 75 g$ & & 14.85 & 1.84 & 0.871 & 0.000 \\
\hline Ir41t.2 & & 13.55 & 1.56 & 0.631 & 0.000 \\
\hline Ir100h & & 2.81 & 1.53 & 0.602 & 0.000 \\
\hline Obp10 & 2159.9 & 1222.8 & 2.36 & 1.23 & 0.00 \\
\hline Obpl & 12041.9 & 5645.9 & 2.23 & 1.15 & 0.00 \\
\hline & 13545.9 & 7739.3 & 1.84 & 0.87 & 0.00 \\
\hline & 18361.3 & 13074.8 & 1.47 & 0.56 & 0.00 \\
\hline & 523.8 & 336.5 & 1.63 & 0.70 & 0.00 \\
\hline Obp26 & 318.5 & 127.7 & 2.65 & 1.36 & 0.00 \\
\hline Obp5 & 14868.2 & 12083.9 & 1.29 & 0.37 & 0.00 \\
\hline Obp25 & 649.0 & 440.2 & 1.55 & 0.63 & 0.00 \\
\hline Obp13 & 321.7 & 221.5 & 1.56 & 0.62 & 0.00 \\
\hline Obp2 & 7817.9 & 7090.3 & 1.16 & 0.21 & 0.00 \\
\hline Obp56 & 2.2 & 1.2 & 1.97 & 0.90 & 0.00 \\
\hline
\end{tabular}


Table 1 Olfactory and gustatory genes that are significantly enhanced in the female antennae of An. gambiae vs An. quadriannulatus (Continued)

\begin{tabular}{|c|c|c|c|c|}
\hline Gr52 & 7.83 & 0.40 & 19.70 & 4. \\
\hline Gr51 & 3.65 & 0.55 & 6.62 & 2 \\
\hline Gr49 & 2.55 & 0.44 & 5.87 & 2 \\
\hline Gr48 & 2.50 & 0.68 & 3.70 & \\
\hline Gr24 & 4.78 & 1.75 & 2.73 & \\
\hline Gr50 & 1.77 & 0.69 & 2.56 & 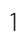 \\
\hline Gr23 & 4.75 & 1.91 & 2.49 & \\
\hline
\end{tabular}

the antennae of either species (0.13 and 0.18 RPKM, Additional file 5: Table S1).

Or expression in the antennae and palps is highly correlated in $A n$. gambiae $\left(R^{2}=0.80\right.$, Figure $\left.5 \mathrm{~A}\right)$, but considerably less so in An. quadriannulatus $\left(R^{2}=0.57\right.$, Figure 6A). Of the 17 Ors significantly enhanced in An. gambiae antennae, most are enhanced in the palps of this species compared to An. quadriannulatus as well. However, there are two notable exceptions; Or8, which shows 3.8-fold up-regulation the An. gambiae antennae, is expressed 4.9-1 he of An. quadriannulatus. It is also ne of most abundant Ors in the palps of th ter spe_res. Similarly, Or28 is significantly 2.0-fold enhan in An. gambiae antennae, but 6.1-fold enbance in the palps of An. quadriannulatus where it is the or $\quad$ highly expressed specific Or.

Not surprisingly, ven the 2.8-fold higher overall level of Or expres $\quad 20 \mathrm{sp}$ ecific Ors are significantly enhanced in

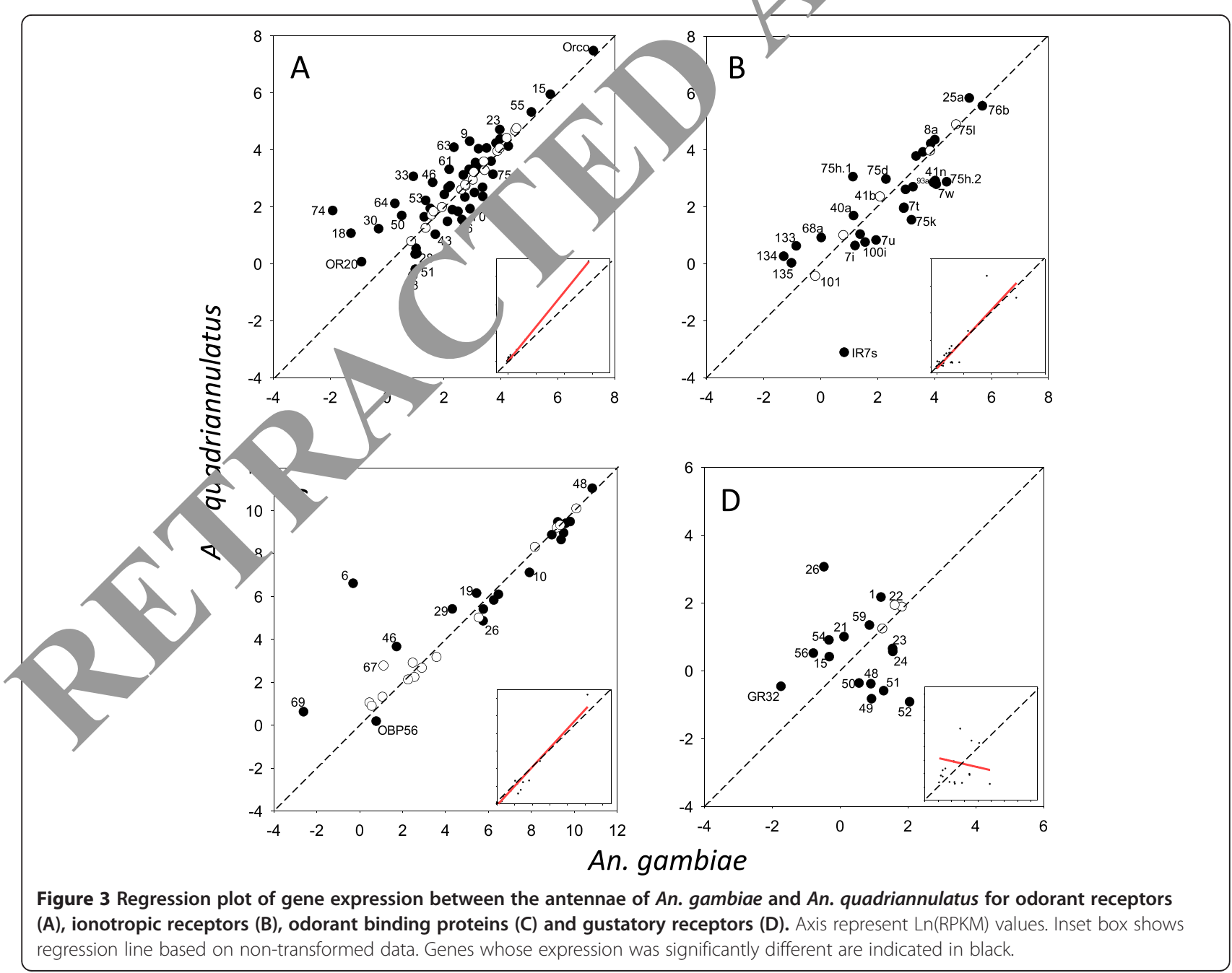




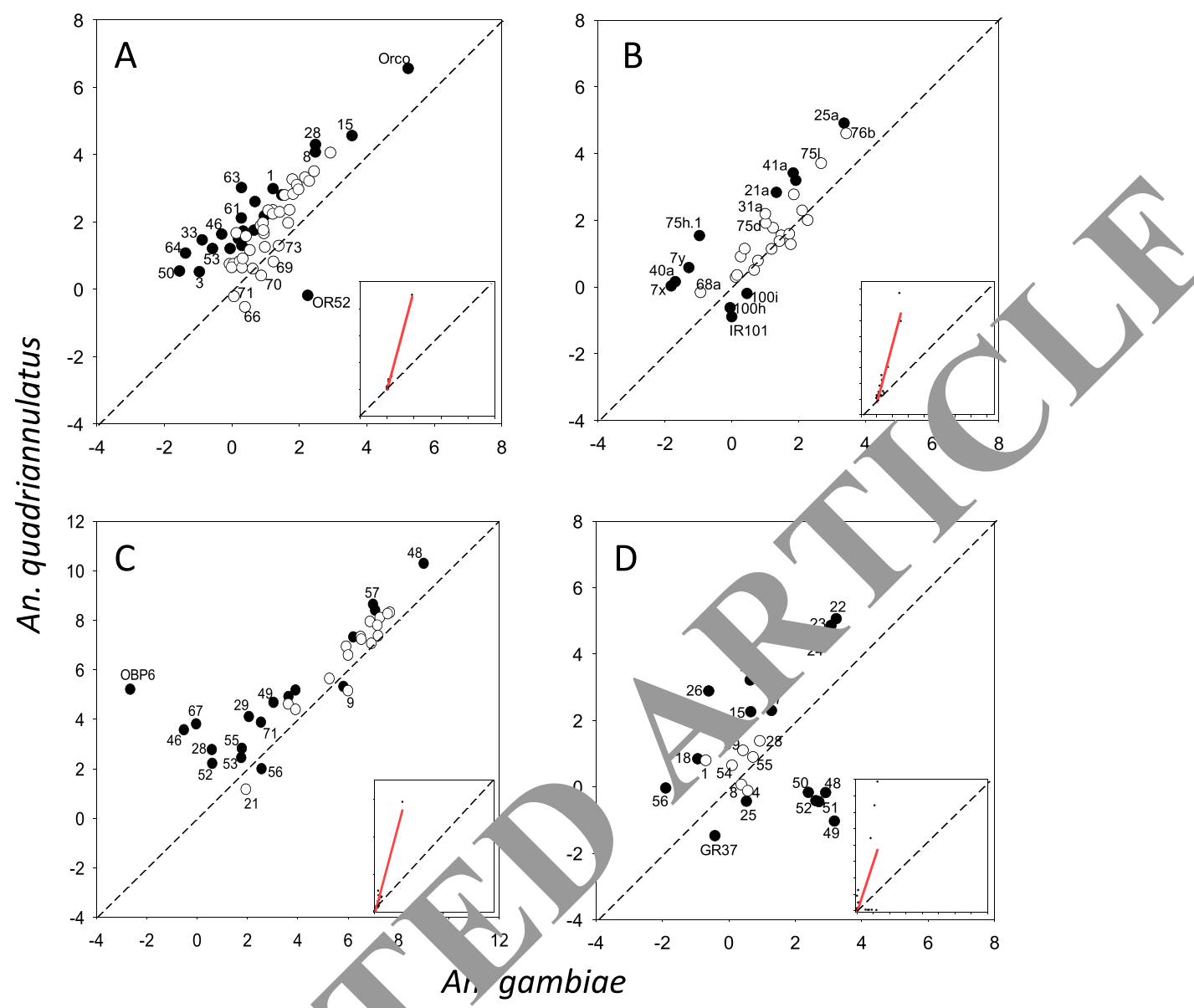

Figure 4 Regression plot of gene expression b tween $t_{\text {. }}$ naxillary palps of An. gambiae and An. quadriannulatus for odorant receptors (A), ionotropic receptors (B), odc ant binding pr jteins (C) and gustatory receptors (D). Axis represent $L n(R P K M)$ values. Inset box shows regression line based on no transformed data. Genes whose expression was significantly different are indicated in black.

the palps of An. quadriannulatis yon. gambiae. With the exception of $\mathrm{Or} 8$ an 28, these are also enhanced in the antennae of this $r$ cies or are not expressed in either (Or3 and 5). Over 1 , the rrelation between Or expression in the palps $\left(R^{2}-80\right.$, Figu, $\left.4 \mathrm{~A}\right)$ of the two species is less than for the antenr $\left(R^{2}=0.94\right.$, Figure $\left.3 \mathrm{~A}\right)$.

\section{lonotrop resptors}

Th-otal en al expression of Irs is similar between recit $(1,28,0$ vs 1,232 RPKM in An. gambiae and An. $q_{4}$ rum ulatus respectively), with a regression slope of 1.07 Igure 3B). Of the 44 annotated Irs, 29 are expressed in the female antennae of An. gambiae and 32 are expressed in An. quadriannulatus (Additional file 5: Table S1). Ir 25a, one of the co-receptors, is by far the most highly expressed $I r$ in both species. However, both species also express $\operatorname{Ir} 76 b$ at very high levels. This gene has been considered a putative co-receptor [26], but which was more recently proposed to encode a $\mathrm{Na}^{+}$leak channel which in Drosophila also plays a role in salt detection [41]. A total of 15 Irs are significantly upregulated in An. gambiae antennae, with nine (Ir75h.2, $7 t, 7 w, 41 c, 41 n, 75 g, 75 k, 93 a$, and 100a) standing out by being both considerably enhanced ( $>1.8$-fold), as well as among the more abundant Irs (Figure 3A, Additional file 5: Table S1). Twelve Irs are significantly enhanced in the female antennae of An. quadriannulatus. Only two specific ionotropic receptors, Ir75d and 75h.1, are considerably up-regulated (>1.9-fold) and abundant (>19.5 RPKM) in this species. Similarly to Or expression, Ir expression is highly correlated between species $\left(R^{2}=0.79\right.$, Figure $\left.3 \mathrm{~B}\right)$.

The total $I r$ expression is much lower in the palps than the antennae (slope $=0.115$ for An. gambiae, Figure 5B, and 0.384 for An. quadriannulatus, Figure 6B), but like the Ors is much higher in An. quadriannulatus (regression slope $=3.7$, Figure 4B). Twenty-four Irs are expressed in the palps of An. gambiae, of which only Ir101 is significantly 3.1-fold enhanced in this species, but it is expressed at very low levels in the palps (and antennae) of both species 


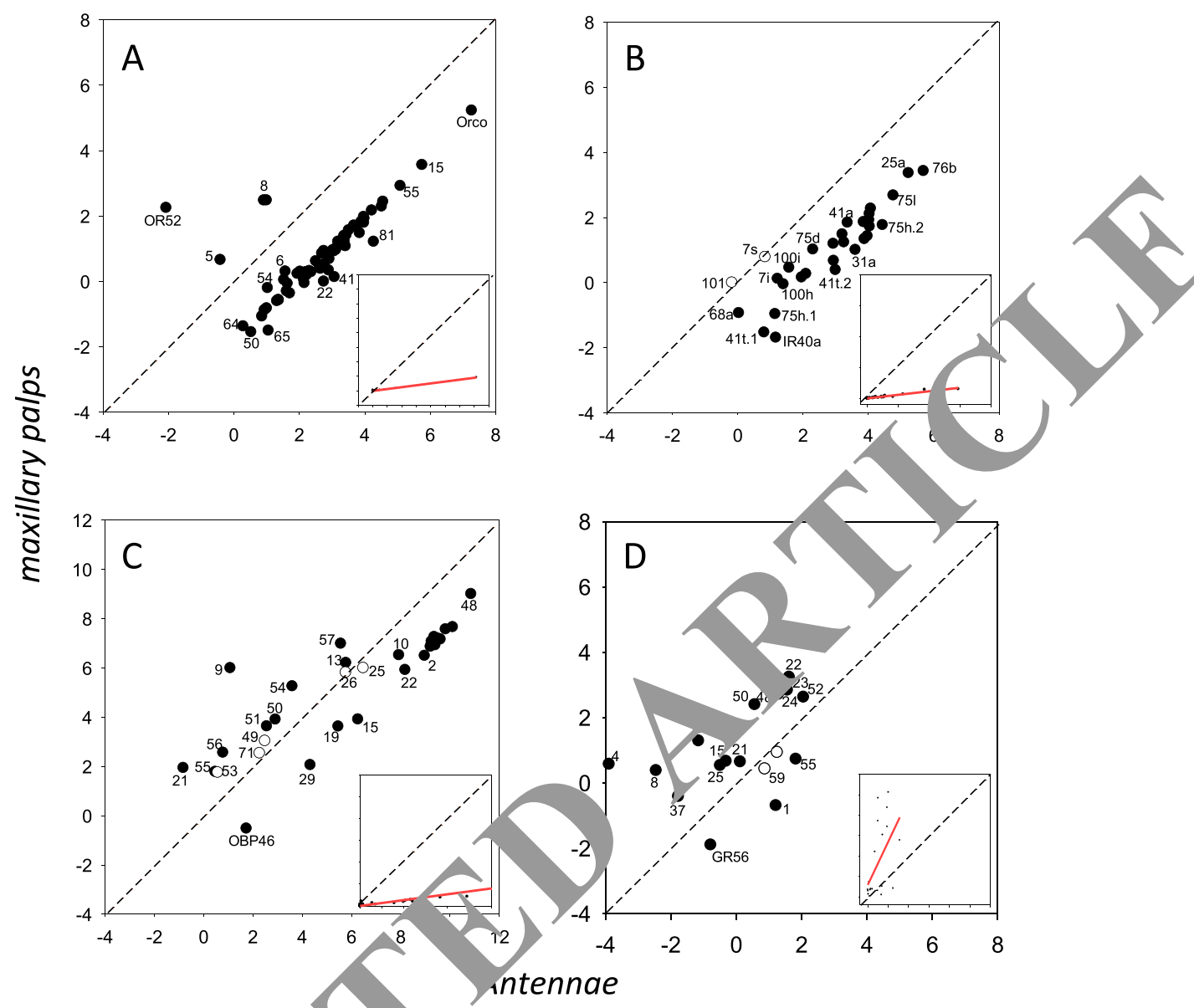

Figure 5 Regression plot of gene expression b tween $\mathrm{t}$. רntennae and maxillary palps of An. gambiae and for odorant receptors (A), ionotropic receptors (B), odorant bindir g proteins (C), nd gustatory receptors (D). Axis represent Ln(RPKM) values. Inset box shows regression line based on non-transformed da. Genes whose expression was significantly different are indicated in black.

(Table 2, Additional file 6: Taple None of the 15 significantly enhanced in $1 n$. gambiae antennae are significantly ent ced in its palps. The expression of eight Irs is signific ty enhanced in the palps of An. quadriann tus. Six it these are also significantly enhanced in the an nae of this species. Ir expression in the palp is highly o, orrelated between the two species $\left(R^{2}=0.0 \quad F_{\text {soure }} 4 \mathrm{~B}\right)$, as well as between the antennae and alps the two species, with $R^{2}=0.92$ for $A n$. rmb ie anc $R^{2}=0.98$ An. quadriannulatus (Figures 5B a of (wee Table 3).

\section{Odorant binding proteins}

As expected based on OBP function, Obp expression in the antennae is considerably higher than that of the Ors and Irs (as much as 51,541.1 RPKM in An. gambiae and 61,872.7 RPKM in An. quadriannulatus, Figures $3 \mathrm{C}$ and $4 \mathrm{C}$ ). In fact, $\mathrm{Obp} 48$ is by far the most highly expressed gene in the antennae of both species, and nine of the top 15 most highly expressed genes are Obps
(Additional file 5: Table S1). That being said, only 27 and 29 of the 57 putative Obps were detected in An. gambiae and $A n$. quadriannulatus female antennae.

The overall level of antennal Obp expression is similar in An. gambiae and An. quadriannulatus (183,218 vs 172,629 RPKM, slope $=1.08$, Figure 3C). Expression of eleven Obps is significantly enhanced in An. gambiae female antennae, and three abundant odorant binding proteins, Obp1, 3 and 10 are more than 1.8-fold enhanced in this species (Table 1). The expression of five Obps was significantly higher in An. quadriannulatus, but of the three that were considerably up-regulated ( $>1.9$-fold), only Obp19 was expressed at any appreciable level (464.8 RPKM). Similarly to Or and Ir expression, antennal $\mathrm{Obp}$ expression was highly correlated between species $\left(R^{2}=0.95\right.$, Figure 3C).

Also consistent with $\mathrm{Or}$ and $\mathrm{Ir}$ expression, the $\mathrm{Obp}$ abundance in the palps is considerably lower than in the antennae (slope $=0.133$ for An. gambiae and 0.411 for An. quadriannulatus, Figures 5C and 6C). Again similar 


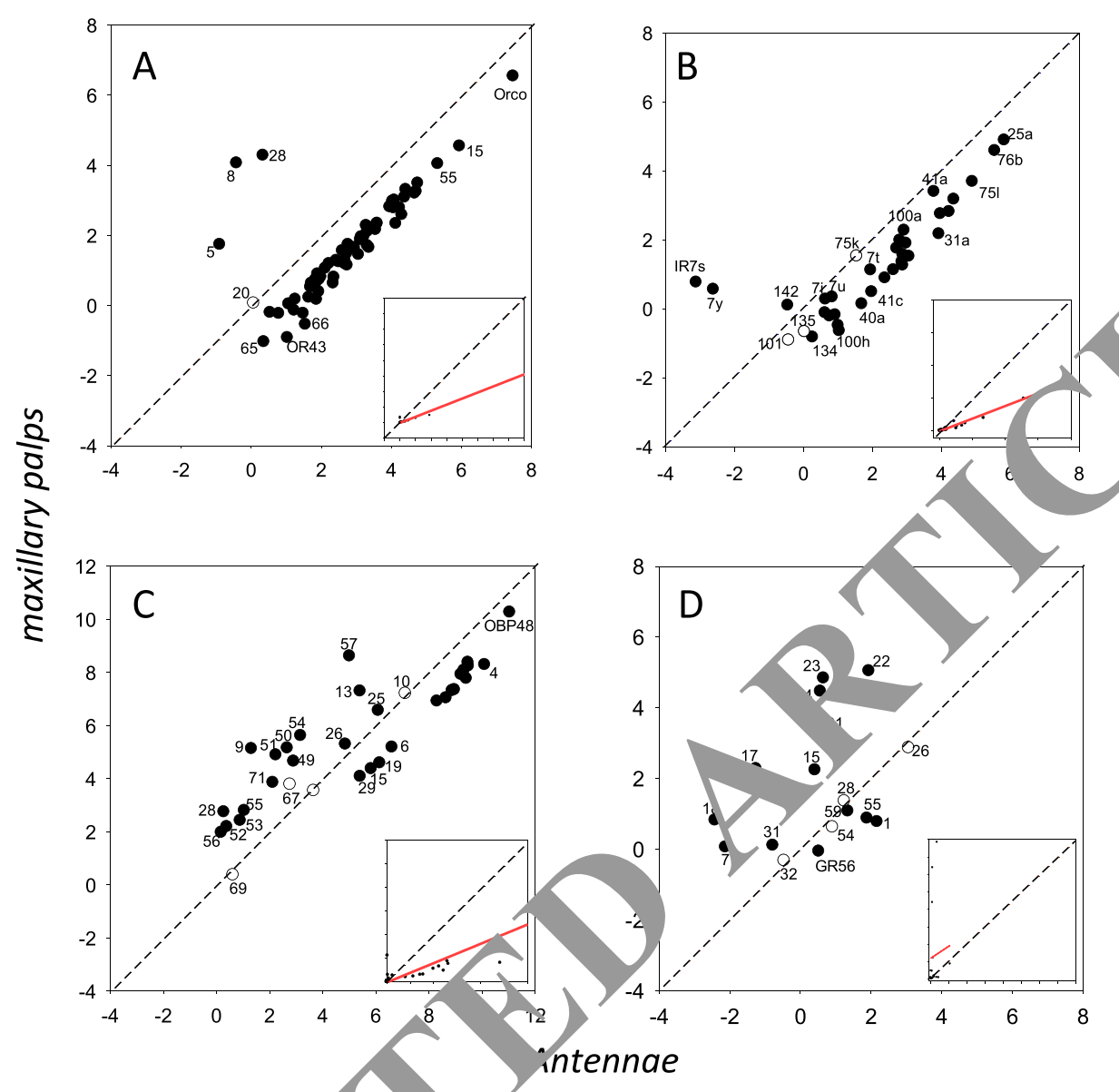

Figure 6 Regression plot of gene expression bet (veen antennae and maxillary palps of An. quadriannulatus and for odorant receptors (A), ionotropic receptors (B), odorntit Dinding $p$. eins (C) and gustatory receptors (D). Axis represent $\operatorname{Ln}(\mathrm{RPKM})$ values. Inset box shows regression line based on non-tran ormed data. Gehes whose expression was significantly different are indicated in black.

to $\mathrm{Or}$ and $\mathrm{Ir}$ expression, the rall Obp expression is several folds higher in the palps or quadriannulatus as compared to $A n$. gr. ue (s ope $=3.39$, Figure $4 \mathrm{C}$ ). Furthermore, $\mathrm{Obp} 4 \mathrm{~s}$, the most abundant gene in the antennae of bot spe ranks 8th in An. gambiae maxillary palps in abundance, whereas it is also the most highly expressed of all genes in An. quadriannulatus.

One relatively abundant odorant binding protein, Obp26 (337.2 RPKM), is expressed at significantly higher levels in An. gambiae palps (2.1-fold), and is also significantly

Table 2 Olf ctory a. qustatory genes that are significantly enhanced in the female

\begin{tabular}{|c|c|c|c|c|c|}
\hline Gene & An. ganibiae rpkm & An. quadriannulatus rpkm & Fold change & Log2 change & $q$ \\
\hline Or52 & 9.55 & 0.83 & 14.92 & 3.255 & 0.000 \\
\hline & 1.01 & 0.41 & 3.10 & 1.459 & 0.003 \\
\hline & 337.15 & 202.39 & 2.10 & 1.046 & 0.000 \\
\hline & 13.03 & 7.30 & 2.23 & 1.108 & 0.001 \\
\hline Gr49 & 24.20 & 0.35 & 68.36 & 5.591 & 0.000 \\
\hline Gr51 & 15.20 & 0.63 & 23.96 & 4.535 & 0.000 \\
\hline Gr52 & 13.88 & 0.65 & 21.25 & 4.421 & 0.000 \\
\hline Gr48 & 18.60 & 0.83 & 22.29 & 4.240 & 0.000 \\
\hline Gr50 & 11.05 & 0.84 & 13.16 & 3.663 & 0.000 \\
\hline Gr25 & 1.72 & 0.64 & 2.66 & 1.368 & 0.004 \\
\hline
\end{tabular}

Maxillary palps of An. gambiae vs An. quadriannulatus. 
Table 3 Summary of olfaction/gustation genes whose expression is significantly different between An. gambiae and An. quadriannulatus, and those who are also $>2$-fold expressed

\begin{tabular}{|c|c|c|c|c|c|}
\hline \multirow[t]{2}{*}{ Gene Family } & \multirow[t]{2}{*}{ Tissue } & \multicolumn{2}{|c|}{ An. gambiae } & \multicolumn{2}{|c|}{ An. quadriannulatus } \\
\hline & & Significant & $>$ 2-fold & Significant & $>$ 2-fold \\
\hline \multirow[t]{2}{*}{ Olfactory Receptors } & Antennae & 17 & 11 & 27 & 13 \\
\hline & Maxillary Palps & 1 & 1 & 21 & \\
\hline \multirow[t]{2}{*}{ Ionotropic Receptors } & Antennae & 15 & 11 & 12 & \\
\hline & Maxillary Palps & 1 & 1 & 8 & \\
\hline \multirow[t]{2}{*}{ Odorant Binding Proteins } & Antennae & 11 & 2 & 5 & \\
\hline & Maxillary Palps & 2 & 2 & 14 & \\
\hline \multirow[t]{2}{*}{ Gustatory Receptors } & Antennae & 7 & 7 & 7 & 6 \\
\hline & Maxillary Palps & 6 & 6 & & 9 \\
\hline
\end{tabular}

up-regulated in the antennae of $A n$. gambiae. Not surprisingly given the 3.4-fold higher level of overall Obp expression in An. quadriannulatus palps, 14 Obps are significantly enhanced in this species, including $\mathrm{Obp} 48$ (Figure 4C, Additional file 6: Table S2). However, the correlation between $\mathrm{Obp}$ expression in the palps of the two species is high $\left(R^{2}=0.95\right.$, Figure $\left.4 C\right)$, and there is also a strong correlation between $\mathrm{Obp}$ expression in the antennae and palps for both species $\left(R^{2}=0.90\right.$ for $A n$. gambiae and $R^{2}=0.88$ for An. quadrianulatus, Figures $5 C$ and 6C).

\section{Gustatory receptors}

The gustatory receptors (AgGrs) are expres $d$ at vel low levels in the antennae of both species, total RPKM values of 57 and 71 in An. gambiae ar $d A n$. quadriannulatus respectively (Fig es $3 \mathrm{D}$ ) and 4D, Additional file 5: Table S1). None-the th expression of seven AgGrs is significantly hanced in An. gambiae, and the same number is signific... up-regulated in An. quadriannulatus. estin ly, five AgGrs that are significantly enhan in $4 n$ gambiae (AgGr48-52) are not express $f$ in quadriannulatus, although the expression these $\xi$ hes in An. gambiae is low as well, ranging $\mathrm{t}_{h} \quad 1.8$ to 7.8 RPKM. To compare, ranking these with the Ors in level of abundance would C. $A \xi G r 52$ in $44^{\text {th }}$ position. Two AgGrs, $A g^{\top}{ }^{-}$ana $G / 26$, stand out in the An. quadriannulatus ten al data.set. They are relatively abundant in this speC1 8.1 und 21.3 RPKM) and significantly up-regulated (>2. Jid). In contrast to the olfaction gene families, little correlation exists between $\mathrm{AgGr}$ expression in the antennae of the two species $\left(R^{2}=0.01\right.$, Figure $\left.3 \mathrm{D}\right)$.

Only 18 out of 60 annotated AgGrs are expressed in the palps of An. gambiae, and 15 are expressed in An. quadriannulatus palps (Figure 4D, Additional file 6: Table S2). The three AgGrs responsible for $\mathrm{CO}_{2}$ detection in mosquito palps (AgGr 22, 23 and 24) are by far the most highly expressed AgGrs in An. quadriannulatus. Interestingly, the expression level of the recep or genes is between 5.1 and 6.1-fold higher in this cies, but is on par with the expression of other jGrs, such as AgGr48 and 49, in An. gambiae. Overa th ession slope between the two species for the $\mathrm{p}$ s is 3.03 (Figure 4D), indicating a much his expression in An. quadriannulatus, but this is ent reiy a a to the $\mathrm{CO}_{2}$ receptors.

Probably the most striking result from the palp data Se, a set of species-specific AgGrs in An. gambiae. The ve up-regulated gustatory receptors from the Sambiae antennae (AgGr48-52) are in fact highly abandant in the palps of this species $(11.1<\mathrm{RPKM}<24.2$, Table 2). Interestingly, they are all but absent from the palps of An. quadriannulatus ( $<0.84$ RPKM).

Similarly, four $\operatorname{AgGrs}(15,17,21$, and 26) are abundant and up-regulated in An. quadriannulatus palps $(9.5<\mathrm{RPKM}<24.7$, > 4.9-fold). These genes are all at very low levels in $A n$. gambiae palps, with $A g G r 26$ being unique to $A n$. quadriannulatus. Interestingly, this gene is also expressed at high levels in the antennae of An. quadriannulatus (21.3 RPKM).

\section{Discussion}

Because of An. gambiae's odor-mediated host seeking behavior [1], it is expected that its preference for human hosts has a strong genetic basis in its olfactory system. This system is primarily housed in the antennae, but the maxillary palps are also involved [14]. In this study a comparison of the olfactory organ transcriptomes of the anthropophilic An. gambiae and its zoophilic sibling species $A n$. quadriannulatus identified species-specific patterns of olfaction gene expression. Even though the expression profiles of olfaction genes are highly correlated between species, clear differences were observed which identify olfaction genes that may play an important role in differential host preference.

The olfactory system of Anopheles mosquitoes plays a role in at least two other aspects of their biology; finding a sugar source, most often nectar, and identifying oviposition 
sites. No data is available on how often or from what source An. quadriannulatus females obtain sugar meals. However, An. gambiae starts ignoring honey volatiles five days after emergence and responds almost exclusively to human odor at that point [42]. Our experience in the laboratory indicates that An. quadriannulatus also switches to host seeking around this time. The larval ecology of both species appears to be similar, with both breeding in shallow, open, sunlit fresh water pools [43,44], and in any case oviposition-site searching does not commence until 48 hours post-blood feeding. Therefore, although we cannot rule out that the differences in olfaction gene expression between the two species are due to biological differences other than host-seeking, there is no data to suggest that such differences are substantial. In addition, the use of 6-day old females in our study optimizes our ability to detect differences in olfaction gene expression that are related to host-seeking [45].

In the antennal transcriptome, seven Ors (Or36, 45, $66,69,70,73,75)$ and nine $\operatorname{Irs}(\operatorname{Ir} 75 h .2,7 t, 7 w, 41 c, 41 n$, $75 g, 75 k, 93 a, 100 a)$ stand out by being among the more highly expressed receptor genes, while also being considerably up-regulated in An. gambiae (1.8 to 4.7-fold). We speculate that the enhanced expression of some of these genes in An. gambiae contributes to an increased sensitivity to human odor. Divergence in olfaction gene exr 1 ession associated with host specialization has been ol vit $\mathrm{d}$ between closely related Drosophila species thr. feea n different host plants. Antennal expression of s differe, markedly between the generalists $D$. meianog ter, $D$. simulans, and their specialist sister-s secies $D$. sec rellia, and as many as $53 \%$ of the Ors were d erentially expressed between species pairs [32].

Previous studies have exam the response of 56 AgOrs to a wide range of dy 5 [24,25]. These included 11 of the $17 \%$ hanced in An. gambiae in the present study. Only vur nocentors showed a positive response to any $c_{1}$ the ted odorants. The exposure of Or75 to eight 14 an vola es led to a small to moderate increase in the fir. rate of the neuron [24]. Or36 has a very narrow tuning c, r ve and responded strongly to only two of $t$ ted odorants, however neither of which are of 1 man igin [25]. Or65 responded mildly to one 1 uma odor ant (4 methylphenol), as well as to several o. Crunicals [24]. Finally, Or8 on the other hand resp ded strongly to two known human odorants, 1-octen-3-ol and 1-hepten-3-ol [24,25]. However, for many of these human volatiles it is not known if they are unique to humans. For example 1-octen-3-ol is exhaled by bovids as well, and is a common compound produced by mushrooms [46]. Finally, it should be kept in mind that 346 volatiles have been identified in human sweat [7], and only a small subset of these volatiles were tested on these Ors.
Expression differences in Obps may also play a role in the human host preference of An. gambiae. Several highly expressed $\operatorname{Obps}(1,3,10)$ are enhanced (1.8 to 2.4-fold) in the antennae of An. gambiae, whereas no abundant Obps are substantially higher expressed in An. quadriannulatus. The presence of specific od orantbinding proteins is well-known to impact be avior in Drosophila. Flies carrying LUSH, a mutant ', are defective in detecting an aggregation pheromone [4, $\mathrm{d}$ Obp57d and Obp57e are involved in lifferer ces in oviposition behavior between Drossprila cies [48].

Importantly, our data shed new ight on the role of the maxillary palps in odor detec $n$ in these species. Lu et al. [14] concluded that rela. small repertoire of Ors is responsible for olfactio. oding in the maxillary palps, although it was ou that in Culex quinquefasciatus the maxillary palps are bro spectrum odorant detectors [49]. A previo's a lysis on the transcriptome of $A n$. gambiae maxn v indicated the expression of relatively small o repertoire [20], with only four Ors expressec 1 RIKM. Those data contrast with our results, in whic, 49 Ors were detected in the palps of this species Although it is not clear at what level the $\mathrm{ex}_{\mathrm{H}}$ ssion of receptors is biologically relevant, 19 of these Ors are expressed at $>4$ RPKM, suggesting the h ' ns may be able to detect a suite of odors. Possible ressons for these contrasting results between the two studies may be that we conducted our dissections during the early dark cycle, and included replicates, which is recommended for obtaining reliable RNAseq data [50].

Another interesting feature of our data is the several fold higher overall expression of the three olfaction gene families in the maxillary palps of An. quadriannulatus compared to An. gambiae. Clearly, the maxillary palps of An. quadriannulatus are considerably more important component of this species' olfactory olfaction system than is the case for An. gambiae.

While no An. gambiae specific olfaction genes were identified in the antennae, an analysis of the maxillary palp transcriptome revealed several An. gambiae specific chemosensory genes. Or52, the seventh most abundant $\mathrm{Or}$ in the $A n$. gambiae palps, is not expressed in $A n$. quadriannulatus. Interestingly, this gene is also absent from the antennae of An. gambiae. This indicates that this maxillary palp receptor could play a species-specific role in An. gambiae's biology, and thus may possibly be involved in human host preference. Unfortunately, this Or was not including in the odorant affinity studies discussed above [24,25].

Additionally, the expression pattern of several AgGrs indicates that they play a species-specific role in olfaction. AgGr48-52 are specific to An. gambiae, and these five AgGrs are expressed at relatively high levels in the maxillary palps, indicating a functional role of the receptors encoded 
by these genes. With the exception of AgGr22-24, which together encode the heteromeric $\mathrm{CO}_{2}$ receptor [14,51], gustatory receptors are generally considered to be primarily involved in gustation. However, the fact that AgGr48-52 are expressed in both the antennae and maxillary palps of An. gambiae suggests a role in olfaction for these genes. These genes are located in tandem on the chromosome $2 \mathrm{R}$ and each pair is separated by only 46 to $326 \mathrm{bp}$. Therefore, the expression of these genes is likely controlled by the same regulatory elements. Additionally, $A g G r 26$ is specific to An. quadriannulatus. It is expressed at high levels only in the maxillary palps and the antennae of this species, suggesting a species-specific role. Therefore, these gustatory receptors may play a significant role in the behavioral differentiation between An. gambiae and An. quadriannulatus.

The several fold higher expression of olfaction genes in the palps of An. quadriannulatus dominates the comparison between the palps of the two species. Nevertheless, Obp26 and Obp56 are more than 2-fold enhanced in the maxillary palps of An. gambiae. Interestingly, both are enhanced in the antennae of this species as well, although Obp56 is expressed at very low levels in this organ.

Several other noteworthy observations result from these data. The expression of Orco and the Ors is $18 \%$ to $26 \%$ higher in the antennae of An. quadrian at Although the antennal sensilla of An. quadriarmu is were found to outnumber those of $A n$. $g$ ran iae, the density is actually similar in both species [32], $\mathrm{h}$ "cating that this difference is not explained $b$ differences, $n$ the antennal morphology. Furthermor the overall level of $I r$ and Obp expression is actuall An. gambiae antennae. This nlies that the overall sensitivity to the odorants detected,y is is higher in $A n$. quadriannulatus antenn

The expression of a $\mathrm{C}$ receptor genes $\mathrm{AgGr} 22-24$ in the maxillary palps both species differs markedly. These genes ar. pressea etween 5.1-6.1 fold higher in An. quadrianaula which greatly exceeds the overall higher le el of expres,on of olfaction genes in the palps of this gav'iae. 1 'oes activate and guide it towards a human for ource but at this point other semiochemicals bu me unportant [53]. In contrast, $\mathrm{CO}_{2}$ is highly attra $\checkmark$ to An. quadriannulatus, which has a more catholic host preference [38]. Our data suggest that the lesser attraction of An. gambiae to $\mathrm{CO}_{2}$ is accompanied by a lower sensitivity to $\mathrm{CO}_{2}$. It has been suggested that anthropophilic mosquitoes primarily use $\mathrm{CO}_{2}$ to detect hosts as a long distance cue [54]. Given the smaller amount of $\mathrm{CO}_{2}$ produced by a human vs. the preferred host of An. quadriannulatus; a bovid, and the relatively low expression level of the $\mathrm{CO}_{2}$ receptor genes in $\mathrm{An}$. gambiae, this species either relies little on $\mathrm{CO}_{2}$ for its long range attraction, or is incapable of detecting hosts from the same distances as An. quadriannulatus.

Although the An. quadriannulatus strain examined in this study showed a preference for bovine hosts, this species did not distinguish between human and con'sweat in an olfactometer in a previous study [4]. Furt nermore, when offered a choice of a human or equal size alf it blood fed equally on both [3]. This suggests tha $1 / n$. quadriannulatus has a wider host prefer e and 's more of a generalist than An. gambiae. This is c ist nt with its much higher level of express on of the $\mathrm{LO}_{2}$ receptor genes. However, the large umber of olfaction genes with enhanced express in quadriannulatus indicates that it, like $A n$. gam e, likely responds to a complex blend dy $1 \mathrm{~h}$ host şeking, similar to $A n$. gambiae [12,55].

Rinker et al to recenty compared the daytime transcriptomes of Atennae of An. gambiae and An. quadriannula Their results correspond roughly with ours linear/ regression analyses of the day-time olfaction expression with the early dark phase reported he re, resulted in $\mathrm{R}^{2}$ values of $0.74-0.78$ for the thi olfaction gene families in An. gambiae, and 0.76-0.91 in A, quadriannulatus. That being said, a few notable ep ions were observed. For example, the expression ditierences for Or66, 73 and Obp26 was much less pronounced during the daytime. For a few genes, e.g. $\operatorname{Ir} 75 k$, $7 t$ and $75 g$ the expression pattern was even reversed. Similarly, several olfaction genes showed differential expression during the day-time, but not during dark cycle (e.g. Obp2 and 13). The expression of Orco and a variety female antennae Obps in female Anopheles gambiae fluctuates throughout the circadian cycle. Expression of these olfaction genes was generally found to be highest during the early stage of the dark phase, and therefore seems to be correlated with the female's host seeking activity [37]. However, a comparison between light and dark cycle transcriptomes, suggests that the expression pattern of olfaction genes do not all follow the same diel expression cycle.

Ionotropic receptors have been divided into "antennal" and "divergent" IRs depending on whether they are expressed in the antennae of Drosophila [16]. It was suggested that this distinction held across a wide range of insects and that divergent IRs play a predominant role in gustation rather than olfaction. Additionally, it was found that antennal IRs tend to be more conserved than the divergent IRs. However, this classification has limited relevance to the expression pattern observed in the antennae of An. gambiae. Of the expressed Irs, 17 were classified as antennal, and 14 as divergent IRs, although of the 14 Irs not expressed in the antennae, 12 are divergent IRs. 


\section{Conclusion}

Our data identifies potential human host preference genes in the malaria vector $A n$. gambiae, but also provides new insight into the importance of the maxillary palps in the olfactory system. The palps are where the most dramatic difference in chemosensory gene expression is observed between the anthropophilic An. gambiae and the zoophilic An. quadriannulatus, with several highly expressed receptor genes that are specific to either species. Finally, the expression patterns of several AgGrs strongly suggest a species-specific role for them in the olfaction system of An. gambiae.

\section{Ethics statement}

Colonies of Anopheles mosquitoes were kept following the Arthropod Containment Guidelines established by The American Committee of Medical Entomology of the American Society of Tropical Medicine and Hygiene. The behavioral experiments were conducted in the Laboratory of Entomology at Wageningen University in the Netherlands. Approval to obtain an odor sample from a cow was obtained from the Animal Use Committee of Wageningen University.

\section{Methods}

\section{Mosquito rearing}

Laboratory strains of An. gambiae M form (G. UA recently proposed to be named An. coluzzii [56], It originally collected in Suakoko, Liberia, as Il as $A_{n}$ quadriannulatus (SANQUA) establisher fron female mosquitoes collected in Sangwe, Zimb owe were re, ed in the insectaries at Wageningen Univer: $y$, The Netherlands (host choice experiment) and Texa $\& M$ University, College Station, TX, USA (RNA analyses). Rearing conditions were $25^{\circ} \mathrm{C}, 75-85 \%$ relative hy. .y and a light:dark photoperiod of 12 hour male mosquitoes were blood fed on defibrinated $r$ ? it $b$ and us a membrane feeding system. Larvae we mai ined at densities of approx. 150 per $2 \mathrm{~L}$ contain. nd fed fit cy ground fish food (Tetramin, Melle, Germany). vae were collected and placed into cages at densities of th $\sigma$ cups of 150 pupae per cage.

For $1 \mathrm{t}$, toes used in RNAseq analyses, cages were che ${ }^{-1}$.nd da for newly emerged mosquitoes. To ensure osq toes yere the same age, pupae that did not eclose w Lrancerred to new cages. Male and females mosquitoes ke kept together in a cage and fed a $5-10 \%$ sucrose solution for six days until tissue dissections. Hence, females were given an opportunity to mate, but not to blood-feed. We checked the insemination rate in $50 \mathrm{An}$. gambiae females at day 6 and found it to be high (82\%).

\section{Dual odor-choice assay}

A total of 750 female An. gambiae and $330 A n$. quadriannulatus females were tested to determine the odor preference of the two species in laboratory conditions. Mosquitoes were put at a density of 75-80 in release cages for use in a dual-choice olfactometer [57] the night before experiments, and provided with a wet cotton ball for hydration. Human and cow odor traps were prepared on the morning of the experiments. Human odor was dorived from the socks worn by volunteers for 24 hours and cow odor was derived from a panty hose tied around 1 eg of a cow for 24 hours. Odor sources were switched be the left and right port of the olfactometer tween uns. A single, centrally placed $\mathrm{CO}_{2}$ plume vas use s a tivator. Conditions during the experim nts were as follows: temperature $=26-28^{\circ} \mathrm{C}$, humidity $575 \%$ in side olfactometer, $80 \%$ in front of port hol air- $\quad$ i $018-0.22 \mathrm{~ms}^{-1}$, and released $\left[\mathrm{CO}_{2}\right]=4.5^{\circ}$. Mosc oes were released into the olfactometer duri g dark-cycle for $15 \mathrm{~min}$. under semi-dark conditions. Mos, toes remaining in the wind tunnel after the exp. ment were disposed of.

\section{Molecular methoo}

Female $\mathrm{m}$ itoes were killed shortly after the start of the dark cyce placing them at $-20^{\circ} \mathrm{C}$. This is when anophelines begin their host searching activity and when On expression in An. gambiae peaks during the circadian ythm [37]. The antennae and maxillary palps were - aved from frozen mosquitoes placed on dry ice and were stored in RNAlater (Ambion). Between 600 to 800 6-day old females were dissected for each replicate and three replicates per species were included for a total of six samples per species. Samples were stored at $4^{\circ} \mathrm{C}$ for 24 hours, before RNAlater was removed and stored at $-80^{\circ} \mathrm{C}$ until RNA extraction.

Total RNA was isolated from each sample using miRNeasy (Qiagen) columns according to the protocol supplied by Qiagen. RNA quantity was initially verified using a Qubit fluorometer (Life Technologies). Next, RNA was further quantified using a NanoDrop spectrophotometer (Thermo Scientific) and the quality assessed using RNA Pico LabChip analysis on an Agilent BioAnalyzer 2100 (Agilent Technologies) by the Agrilife Genomics Center at Texas A\&M University.

mRNA was isolated from $1 \mu \mathrm{g}$ of total RNA and cDNA libraries were prepared using an Illumina TruSeq RNA Library kit (Illumina). Each single-end library contained two/three replicates that had been given a unique tag using barcode sequences supplied by the library kit. Each library was sequenced on a single lane of an Illumina flow cell and using 50 cycles on an Illumina HiSeq 2000. Preparation and sequencing of libraries were both performed by the University at Buffalo Next-Generation Sequencing and Expression Analysis Core Facility. Approximately 50-70 million reads with an average read of 51 base pairs were generated for each replicate sample and used for further analysis. 


\section{RNA sequencing analyses}

Read quality was assessed using FastQC (ver 0.10.0) and processed using NGS QC toolkit [58] with at least 80\% of the reads had Phred $>30$ (raw reads Phred quality score $0-40)$. Reads were trimmed and then filtered by length, discarding reads $<40 \mathrm{bp}$. Sequencing reads were mapped to the reference An. gambiae genome (AgamP3; December 2013) using the software package STAR [59]. Alignments were discarded if they had more than two mismatches. Read counts were conducted with HTSeqcount (ver 0.5.4) (http://www.huber.embl.de/users/anders/ HTSeq/doc/count.html). Only reads that aligned to a unique location in the genome were used to calculate the expression levels. Sequence data was obtained for three replicates of the antennae for each species, and for three replicates for the palps. One palp replicate for each species provided poor quality data, and these were therefore discarded from further analyses. Tests for differential expression in the female antennae or palps from An. gambiae versus $A n$. quadriannulatus were performed in the $\mathrm{R}$ package DESeq2 [60]. Size factors for each dataset were calculated to normalize library sizes across replicates, and overall means and variances were determined using a negative binomial distribution model. Genes were considered to be differentially expressed if $\mathrm{q}<0.05$ after correcting for multiple testing. Genes were considered not expressed if RPKM 1 .

To compare the tissue and species effect on the er: 1 gene expression, we computed the correlation cueffic $t$ $\left(\mathrm{R}^{2}\right)$ and slope from a linear regression $\%$ veen $A_{n}$. gambiae versus $A n$. quadriannulatus data sets s well as between maxillary palps and anten ae. Scripts oed to run RNAseq analyses are presented Additipnal file 7. Reads for Obp6 and Obp29 mapped t ultir le locations in the genome, therefore expr ion data for these two genes are unreliable, and not consia.- in this analysis.

\section{Gene ontology analy}

Genes that met che to wing criteria: $q<0.05$, FoldChange $>2, R^{r}, \quad>1$ at cast in one sample, between antenna and ma ry palps of $A n$. gambiae versus An. quodriannulatu were used for gene ontology (GO) a $1 \mathrm{v}$.s. I $7 \mathrm{O}$ Annotation was performed using Bla $\mathrm{GO}, \%$ he gene sequences were retrieved from Inser bl Gen omes release 22 via Biomart (http://metazoa. e mirog/index.html). GO annotation was used for asses cent of the genes differentially expressed in each sample. GO annotation associates analyzed transcripts with terms from hierarchical vocabularies describing, e.g., molecular function or biological process.

\section{Availability of supporting data}

All fastq files containing the raw data were deposited at the NCBI Sequence Read Archive. [http://www.ncbi.nlm. nih.gov/sra?term=SRP050131]. The full gene expression data are available in "Additional file 5" (antennae) and "Additional file 6" (maxillary palps).

\section{Additional files}

Additional file 1: Figure S1. PCA plot showing the antennal and maxillary palps data sets of An. gambiae and An. quadriannulaty in the 2D plane spanned by their first two principal components.

Additional file 2: Figure S2. GO analysis of 608 An. quadriannu genes with $>2$-fold antennal expression compared to in. gambiae, predicting their involvement in molecular functions (a nd biolo

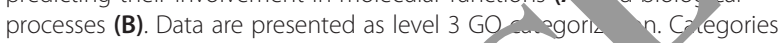
with less than $1 \%$ of representation were grc aped in "othe

Additional file 3: Figure S3. GO analysis 870 An. ga nbiae genes with $>2$-fold maxillary palp expression omp to An quadriannulatus, predicting their involvement in moiec functiv, $(\boldsymbol{A})$ and biological processes (B), and of 787 An. qu aarannu, genes with $>2$-fold maxillary palp expression con to An. 9 ibiae, predicting their involvement in molecular inctic ${ }^{\prime}(C)$ and biological processes (D). Additional file 4: Fio S4. Venn gram showing the overlap in the number of genes cinific tly and more than 2-fold higher expressed in the tissues of eitri

Additional file 5: Ta. \$1, Gene expression data for all genes in the antennae (n gambiat, An. quadriannulatus.

Additional file $\quad$ S2. Gene expression data for all genes in the maxillary palp of An. gambiae and An. quadriannulatus.

Iditional fil 1: Scripts used to run RNAseq analyses.

mpe $\mathrm{ng}$ interests

in thors declare that they have no competing interests.

Authors' contributions

TKH: data collection, analysis and manuscript preparation; LVC: data collection, data analysis and manuscript preparation, GA; data collection, data analysis and manuscript preparation; Sharmila Pathikonda; data analysis and manuscript preparation; WT: supervision and planning of experiments, and manuscript preparation; MAS: conceived, planned and supervised experiments, manuscript preparation. All authors read and approved the final manuscript.

\section{Acknowledgements}

We are grateful to Leon Westerd for assistance with colony maintenance, to Jeroen Spitzen for providing odor samples, and to Craig Coates for providing rearing space. We also thank two anonymous reviewers for their help in improving an earlier version of this manuscript. This work was supported by NIH/NIAID grant 1R01 Al085079 to MAS.

\section{Author details}

${ }^{1}$ Department of Entomology, Texas A\&M University, College Station, TX 77843, USA. ${ }^{2}$ Laboratory of Entomology, Wageningen University, Wageningen, The Netherlands.

Received: 9 September 2014 Accepted: 4 December 2014 Published: 11 December 2014

\section{References}

1. Takken W, Knols BG: Odor-mediated behavior of Afrotropical malaria mosquitoes. Annu Rev Entomol 1999, 44:131-157.

2. Takken W, Eling W, Hooghof J, Dekker T, Hunt R, Coetzee M: Susceptibility of Anopheles quadriannulatus Theobald (Diptera: Culicidae) to Plasmodium falciparum. Trans R Soc Trop Med Hyg 1999, 93:578-580.

3. Pates HV, Takken W, Curtis CF, Huisman PW, Akinpelu O, Gill GS: Unexpected anthropophagic behaviour in Anopheles quadriannulatus. Med Vet Entomol 2001, 15(3):293-298.

4. Pates HV, Takken W, Curtis CF: Laboratory studies on the olfactory behavior of An. quadriannulatus. Entomol Exp App/ 2005, 114:153-159. 
5. Braks MAH, Takken W: Incubated human sweat but not fresh sweat attracts the malaria mosquito Anopheles gambiae sensu stricto. J Chem Ecol 1999, 25(3):663-672.

6. Verhulst NO, Andriessen R, Groenhagen U, Bukovinszkiné Kiss G, Schulz S, Takken W, van Loon JJA, Schraa G, Smallegange RC: Differential attraction of malaria mosquitoes to volatile blends produced by human skin bacteria. PLoS One 2010, 5(12):e15829.

7. Bernier UR, Kline DL, Barnard DR, Schreck CE, Yost RA: Analysis of human skin emanations by gas chromatography/ mass spectrometry. 2 . Identification of volatile compounds that are candidate attractants for the yellow fever mosquito (Aedes aegypti). Anal Chem 2000, 72:747-756.

8. Braks MAH, Meijerink J, Takken W: The response of the malaria mosquito, Anopheles gambiae to two components of human sweat, ammonia and L-lactic acid. Physiol Entomol 2001, 26:142-148.

9. Dekker T, Steib B, Carde RT, Geier M: L-lactic acid: a human-signifying host cue for the anthropophilic mosquito Anopheles gambiae. Med Vet Entomol 2002, 16:91-98.

10. Smallegange RC, Qiu YT, van Loon JJ, Takken W: Synergism between ammonia, lactic acid and carboxylic acids as kairomones in the host-seeking behaviour of the malaria mosquito Anopheles gambiae sensu stricto (Diptera: Culicidae). Chem Senses 2005, 30:145-152.

11. Van den Broek IVF, den Otter CJ: Olfactory sensitivities of mosquitoes with different host preferences (Anopheles gambiae s.S., An. arabiensis, An. quadriannulatus, An. m. atroparvus) to synthetic odours. J Insect Physiol 1999, 45:1001-1010.

12. Mukabana WR, Mweresa CK, Otieno B, Omusula P, Smallegange RC, Loon JJA, Takken W: A novel synthetic odorant blend for trapping of malaria and other African mosquito species. J Chem Ecol 2012, 38(3):235-244.

13. Pitts RJ, Fox AN, Zwiebel $\amalg$ : A highly conserved candidate chemoreceptor expressed in both olfactory and gustatory tissues in the malaria vector, Anopheles gambiae. Proc Natl Acad Sci U S A 2004, 101:5058-5063.

14. Lu T, Qiu YT, Wang G, Kwon JY, Rutzler M, Kwon HW, Pitts RJ, van Loon JJA, Takken W, Carlson JR, Zwiebel L: Odor coding in the maxillary palp of the malaria vector mosquito Anopheles gambiae. Curr Biol 2007, 17:1533 1544

15. Zwiebel $L J$, Takken W: Olfactory regulation of mosquito-host inte tion Insect Biochem Mol Biol 2004, 34:645-652.

16. Croset V, Rytz R, Cummins SF, Budd A, Brawand D, Kaessmar A H, Toby Gibson TJ, Benton R: Ancient protostome origin of chem cory ionotropic glutamate receptors and the evolution of $\mathrm{r}$. sect and olfaction. PLOS Genet 2010, 6(8):e1001064.

17. Li Z-X, Pickett JA, Field LM, Zhou JJ: Identificatic and expression of odorant binding proteins of the malaria-carry g mosquitc Anopheles gambiae and Anopheles arabiensis. Archiv Insed chem Pbysiol 2005, 58:175-189.

18. Siju KP, Reifenrath A, Scheiblich H, Neup Dredel R, Hansson BS, Schachtner J, Ignell R: Neuropeptides in the an. nal lobe of the yellow fever mosquito Aedes aegyr Comp N urol 2014, 522(3):592-608.

19. Hill CA: G protein-couple recep rs in Ar pheles gambiae. Science 2002 298(5591):176-178.

20. Pitts RJ, Rinker DC, ones $P L$, $A$, Zwiebel $L$ : Transcriptome profiling of chemosensor, nendages, malaria vector Anopheles gambiae reveals tissuc ana specific signatures of odor coding. BMC Genomics 2011, 12(1) 71 .

21. Liu C, P,tts RJ, Bohbot JD) Jones PL, Wang G, Zwiebel LJ: Distinct olfactory sign $m$ hani $m$ in the malaria vector mosquito Anopheles aambiat os Biol 2010, 8(8):e1000467.

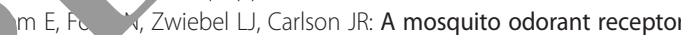
tul d to a component of human sweat. Nature 2004, 427:212-213. ig G, Buscariollo D, Pitts RJ, Wenger H, Zwiebel LJ: The molecula cellular basis of olfactory-driven behavior in Anopheles gambiae lai de. Proc Natl Acad Sci U S A 2008, 105:6433-6438

24. Carey AF, Wang G, Su C-Y, Zwiebel LJ, Carlson JR: Odorant reception in the malaria mosquito Anopheles gambiae. Nature 2010, 464(7285):66-71.

25. Wang G, Carey AF, Carlson JR, Zwiebel LJ: Molecular basis of odor coding in the malaria vector mosquito Anopheles gambiae. Proc Natl Acad Sci U S A 2010, 107(9):4418-4423.

26. Abuin L, Bargeton B, Ulbrich MH, Isacoff EY, Kellenberger S, Benton R: Functional architecture of olfactory ionotropic glutamate receptors. Neuron 2011, 69(1):44-60.

27. Leal WS: Odorant reception in insects: Roles of receptors, binding proteins, and degrading enzymes. Annu Rev Entomol 2013, 58(1):373-391.
28. Vogt RG: Odorant binding protein homologues of the malaria mosquito Anopheles gambiae; Possible orthologues of the OS-E and OS-F OBPs of Drosophila melanogaster. J Chem Ecol 2002, 28(11):2371-2376.

29. Xu PX, Zwiebel LJ, Smith DP: Identification of a distinct family of genes encoding atypical odorant-binding proteins in the malaria vector mosquito, Anopheles gambiae. Insect Mol Biol 2003, 12(6):549-560.

30. Zhou J-J, Huang W, Zhang G-A, Pickett JA, Field LM: "Plus-C" odorant-binding protein genes in two Drosophila species and the malaria mosquit, Anopheles gambiae. Gene 2004, 327(1):117-129.

31. Biessmann $\mathrm{H}$, Nguyen OK, Le D, Walter MF: Microarray-based s, vi a subset of putative olfactory genes in the mosquito Anopheles Insect Mol Biol 2005, 14:575-589.

32. Kopp A, Barmina O, Hamilton AM, Higgins L, Mclntyr Jones C Evolution of gene expression in the Drosophil lfact vster $1 . \mathrm{Mol} B \mathrm{BiO}$ Evol 2008, 25:1081-1092.

33. Dekker T, Ibba I, Siju KP, Stensmyr MC, Han on BS: Olfactory shifts parallel superspecialism for toxic fruit in Drrsoph velanoge ter sibling D sechellia. Curr Biol 2006, 16:101-18,

34. McBride CS: Rapid evolution of nell c. taste receptor genes during host specialization in Dross 'ila sechellic C Natl Acad Sci U S A 2007, 104:4996-5001.

35. McBride CS, Arguello JR: Pive Dro hila genomes reveal nonneutral evolution and the ure of hos specialization in the chemoreceptor super familiy. vetics 107, 177:1395-1416.

36. Rinker DC, Zhou as A, Zwiebel LJ: Antennal transcriptome profiles of anophel. nosquitoes reveal human host olfactory speciali. an in Anop, res gambiae. BMC Genomics 2013, 14(1):1

37. Rund SSC M Mard SM, Collins FH, Duffield GE: Genome-wide profiling of alel a id circadian gene expression in the malaria vector Anopheles cambiae. Proc Natl Acad Sci U S A 2011, 108(32):E421-E430. kker T, Takken W: Differential responses of mosquito sibling species pheles arabiensis and An. quadriannulatus to carbon dioxide, a man or calf. Med Vet Entomol 1998, 12(2):136-140

St arp BL, Quicke FC, Jansen EJ: Aspects of the behaviour of five anopheline species. J Entomo/ Soc Southern Africa 1984, 47:251-258. Pates HV, Curtis CF, Takken W: Hybridization studies to modify the host preference of Anopheles gambiae. Med Vet Entomol 2014, 28(S1):68-74.

41. Zhang YV, Ni J, Montell C: The molecular basis for attractive salt-taste coding in Drosophila. Science 2013, 340:1334-1338.

42. Foster WA, Takken W: Nectar-related vs. human-related volatiles: behavioral response and choice by female and male Anopheles gambiae (Diptera: Culicidae) between emergence and first feeding. Bull Entomol Res 2004, 94:145-157.

43. Coluzzi M: Heterogeneities of the malaria vectorial system in tropical Africa and their significance in malaria epidemiology and control. Bull World Health Organ 1984, 62(suppl):107-113.

44. Gillies MT, Coetzee M: A supplement to the Anophilinae of Africa south of the Sahara. In, Publication of the South African Institute for Medical Research, Johannesburg; 1987:55.

45. Takken W, Klowden MJ, Chambers G: Effect of body size on host seeking and blood meal utilization in Anopheles gambiae sensu Stricto (Diptera: Culicidae): the disadvantage of being small. J Med Entomol 1998, 35:639-645.

46. Ramoni R, Vincent F, Grolli S, Conti V, Malosse C, Boyer F-D, Nagnan-Le Meillour P, Spinelle S, Cambillau C, Tegoni M: The insect attractant 1 -octen-3-ol is the natural ligand of the bovine odorant binding protein. J Biol Chem 2001, 276(10):7150-7155.

47. Xu P, Atkinson R, Jones DNM, Smith DP: Drosophila OBP LUSH is required for activity of pheromone-sensitive neurons. Neuron 2005, 45(2):193-200

48. Matsuo T, Sugaya S, Yasukawa J, Aigaki T, Fuyama Y: Odorant-binding proteins OBP57d and OBP57e affect taste perception and host-plant preference in Drosophila sechellia. PLoS Biol 2007, 5:e118.

49. Syed Z, Leal WS: Maxillary palps are broad spectrum odorant detectors in Culex quinquefasciatus. Chem Senses 2007, 32(8):727-738.

50. Auer PL, Doerge RW: Statistical Design and Analysis of RNA Sequencing Data. Genetics 2010, 185(2):405-416.

51. Jones WD, Cayirlioglu P, Grunwald Kadow I, Vosshall LB: Two chemosensory receptors together mediate carbon dioxide detection in Drosophila. Nature 2006, 445(7143):86-90.

52. Pitts RJ, Zwiebel L: Antennal sensilla of two female Anopheline sibling species with differing host ranges. Malar J 2006, 5:26. 
53. Spitzen J, Smallegange RC, Takken W: Effect of human odours and positioning of $\mathrm{CO} 2$ release point on trap catches of the malaria mosquito Anopheles gambiae sensu stricto in an olfactometer. Physiol Entomol 2008, 33(2):116-122.

54. Takken W: The role of olfaction in host-seeking of mosquitoes: a review. Insect Sci Applic 1991, 12:287-290

55. Verhulst NO, Mbadi PA, Kiss GB, Mukabana WR, van Loon JJ, Takken W, Smallegange RC: Improvement of a synthetic lure for Anopheles gambiae using compounds produced by humanskin microbiota. Malaria J 2011, 10(1):28.

56. Coetzee M, Hunt RH, Wilkerson R, della Torre A, Coulibaly MB, Besansky NJ: Anopheles coluzzii and Anopheles amharicus, new members of the Anopheles gambiae complex. Zootaxa 2013, 3619(3):246-274.

57. Pates HV, Takken W, Stuke K, Curtis CF: Differential behaviour of Anopheles gambiae sensu stricto (Diptera : Culicidae) to human and cow odours in the laboratory. B Entomol Res 2001, 91(4):289-296.

58. Patel RK, Jain M: NGS QC toolkit: A toolkit for quality control of next generation sequencing data. PLoS One 2012, 7(2):e30619.

59. Dobin A, Davis CA, Schlesinger F, Drenkow J, Zaleski C, Sonali J, Batut P, Chaisson M, Gingeras TR: STAR: ultrafast universal RNA-seq aligner. Bioinformatics 2013, 29:15-21.

60. Love Ml, Huber W, Anders S: Moderated estimation of fold change and dispersion for RNA-Seq data with DESeq2. BioRxiv 2014, doi:10.1101/ 002832.

61. Conesa A, Gotz S, Garcia-Gomez J, Terol J, Talon M, Robles M: Blast2GO: a universal tool for annotation, visualization and analysis in functional genomics research. Bioinformatics 2005, 21(18):3674-3676.

doi:10.1186/1471-2164-15-1089

Cite this article as: Hodges et al:: Species-specific chemosensory gene expression in the olfactory organs of the malaria vector Anopheles gambiae. BMC Genomics 2014 15:1089.

\section{Submit your next manuscript to BioMed Central and take full advantage of:}

- Convenient online submission

- Thorough peer review

- No space constraints or color figure charges

- Immediate publication on acceptance

- Inclusion in PubMed, CAS, Scopus and Google Scholar

- Research which is freely available for redistribution 